\title{
S3 Supplement.
}

Excretion, as defined in Figure 1, must be greater than or equal to zero, as herbivores cannot take up inorganic $\mathrm{N}$ from the environment. Because herbivore excretion must be non-negative, the relative $\mathrm{C}: \mathrm{N}$ ratios of plants and herbivores and herbivore metabolism are constrained as follows:

$$
\frac{C N H}{C N P}+\frac{r_{2 H}}{e_{1} r_{1 H} P_{C}} \geq 1
$$

This criterion is intuitive biologically. As the ratio of $C N H / C N P$ decreases, the herbivore must respire the excess carbon as $\mathrm{CO}_{2}$. Therefore the model is sensitive to the values of $r_{2 H}, C N P$ and $\mathrm{CNH}$. High values of herbivore $\mathrm{C}: \mathrm{N}$ or of herbivore respiration relative to plant matter ingestion, or both, contribute to this criterion being satisfied. 